\title{
STUDI PERENCANAAN PENGADAAN SEDIAAN FARMASI DI APOTEK $X$ BERDASARKAN PERATURAN MENTERI KESEHATAN NOMOR 73 TAHUN 2016
}

\author{
Ni Made Irma Febby Prasasti Dewi ${ }^{1 *}$, I Made Agus Gelgel Wirasuta ${ }^{1}$ \\ ${ }^{1}$ Program Studi Farmasi, Fakultas Matematika dan Ilmu Pengetahuan Alam, \\ Universitas Udayana \\ Jalan Kampus Unud-Jimbaran, Jimbaran-Bali, Indonesia \\ 80364 Telp/Fax: 0361-70837 \\ *E-mail: irmafebby02@gmail.com
}

\begin{abstract}
ABSTRAK
Perencanaan dan pengadaan obat merupakan bagian penting dalam tahap pengelolaan obat di Apotek. Perencanaan obat yang tidak tepat akan menyebabkan pemborosan dalam anggaran pengadaan obat, biaya untuk pengadaan akan membengkak, serta terjadi kekurangan maupun kelebihan obat. Pengadaan yang tidak efektif menyebabkan tidak tercapainya ketersediaan obat dalam jumlah yang tepat dengan harga sesuai. Penelitian ini menggunakan metode deskriptif observasional yang dilakukan dengan wawancara terhadap apoteker pengelola apotek dan didukung dengan data kuntitatif yang diambil secara retrospektif dari Apotek X sehingga dapat memberikan gambaran sistem perencanaan pengadaan sediaan farmasi, alat kesehatan dan bahan medis habis pakai di Apotek tersebut. Objek penelitian ini dikhususkan pada Apotek X di Kabupaten Badung, Provinsi Bali. Perencanaan di Apotek X dilakukan dengan mengacu pada Standar Pelayanan Kefarmasian di Apotek yang tertera pada Peraturan Menteri Nomor 73 Tahun 2016 tentang Standar Pelayanan Kefarmasian di Apotek. Metode perhitungan kebutuhan yang digunakan dalam perencanaan adalah metode Proxy Consumption dan metode analisis perencanaan yang digunakan untuk menilai efesiensi perencanaan dan anggaran adalah metode Analisis ABC atau Pareto. Metode tersebut dapat meminimalisir kerugian akibat barang expired serta persentase barang fast moving yang lebih tinggi dari slow moving.
\end{abstract}

Kata kunci: Perencanaan, sediaan farmasi, Apoteker, Apotek, Metode Proxy Consumption, Analisis $A B C($ Pareto $)$

\begin{abstract}
Drug planning and procurement is an important part of the drug management stage at the Pharmacy. Improper drug planning will cause waste in the drug procurement budget, costs for procurement will swell, and there will be a shortage or excess of drugs. Ineffective procurement results in not achieving the availability of drugs in the right amount at the right price. This study uses an observational descriptive method which is conducted by interviewing pharmacists managing pharmacies and supported by quantitative data retrospectively taken from X Pharmacy so as to provide an overview of the procurement planning system for pharmaceutical preparations, medical devices and consumable medical materials at the Pharmacy. The object of this study is devoted to X Pharmacy in Badung Regency, Bali Province. Planning at X Pharmacy is carried out with reference to the Pharmaceutical Service Standards at the Pharmacy which are listed in the Peraturan Menteri Nomor 73 Tahun 2016 concerning Pharmaceutical Service Standards at the Pharmacy. The need calculation method used in planning is the Proxy Consumption method and the planning analysis method used to assess the efficiency of planning and budget is the ABC or Pareto Analysis method. This method can minimize losses due to expired goods and the percentage of fast moving goods which is higher than slow moving.

Keyword: Planning, pharmaceutical preparation, Pharmacist, Pharmacy, Proxy Consumption Method, ABC Analysis (Pareto)
\end{abstract}




\section{PENDAHULUAN}

Farmasi forensik merupakan "the application of science to the law" yang berarti ilmu farmasi yang mempelajari dan menerapkan ilmu pengetahuan dan teknologi kefarmasian untuk kepentingan hukum dan peradilan. Dalam menjalankan pekerjaan kefarmasiannya, apoteker hendaknya didasarkan pada ilmu Farmasi Forensik. Farmasi Forensik bukan hanya berperan dalam penyelesaian suatu kasus hukum semata, melainkan juga melindungi serta menata diri seorang apoteker dalam menjalankan pekerjaan kefarmasiannya agar sesuai dengan peraturan atau regulasi yang berlaku [1].

Berdasarkan Peraturan Menteri Kesehatan Republik Indonesia No 73 Tahun 2016 tentang Standar Pelayanan Kefarmasian di Apotek Pasal 3 Ayat 2 menyebutkan bahwa pengelolaan sediaan farmasi, alat kesehatan, dan bahan medis habis pakai salah satunya adalah tahap perencanaan. Perencanaan merupakan kegiatan penentuan penyusunan daftar kebutuhan obat (jenis dan jumlah) sesuai dengan kebutuhan dan anggaran, sebelum dilakukannya proses pengadaan [2]. Adapun tujuan dilakukannya perencanaan adalah untuk menyusun kebutuhan obat yang tepat dan sesuai dengan kebutuhan untuk mencegah terjadinya kekurangan atau kelebihan persediaan farmasi; menjain stok sediaan farmasi, alat kesehatan dan BMHP tidak berlebih; meningkatkan penggunaan persediaan farmasi secara efektif ;efisien serta memberikan dukungan data bagi estimasi pengadaan, penyimpanan dan biaya distribusi sediaan farmasi, alat kesehatan dan BMHP. Perencanaan dilakukan dengan beberapa tahapan yaitu tahap persiapan, pengumpulan data, penetapan jenis dan jumlah yang direncanakan menggunakan metode perhitungan kebutuhan, evaluasi perencanaan, revisi rencana kebutuhan obat (jika diperlukan), dan apabila apotek bekerjasama dengan BPJS diwajibkan untuk mengirimkan RKO yang sudah yang sudah disetujui oleh pimpinan Apotek melalui Aplikasi E-monev [3].

Menurut Petunjuk Teknis Standar Pelayanan Kefarmasian di Apotek terdapat tiga metode yang dapat digunakan untuk perhitungan kebutuhan pada perencanaan, yaitu Metode Konsumsi, Metode Morbiditas dan Metode Proxy Consumption. Selain perhitungan obat, pada tahap perencanaan juga terdapat analisis atau evaluasi rencana kebutuhan sediaan farmasi yang bertujuan untuk menjamin ketersediaan obat dan efesiensi anggaran. Evaluasi perencanaan tersebut dapat dilakukan dengan berbagai metode, yaitu Analisis ABC, Analisis VEN, dan Analisis Kombinasi [4]. Setelah tahap perencanaan dilakukan, maka dilanjutkan dengan tahap pengadaan.

Pengadaan adalah proses penyediaan obat yang dibutuhkan di Apotek dan untuk unit pelayanan kesehatan lainnya yang diperoleh dari pemasok eksternal melalui pembelian dari manufaktur, distributor, atau pedagang besar farmasi (PBF). 
Landasan hukum dalam proses pengadaan PMK No 73 Tahun 2016 yang mengatur bahwa pengadaan merupakan salah satu tahapan pengelolaan sediaan Farmasi, alat kesehatan, dan BMHP yang mana untuk menjamin kualitas Pelayanan Kefarmasia maka pengadaan Sediaan Farmasi harus dilakukan melalui jalur resmi sesuai dengan peraturan perundang-undangan [2]. Proses pengadaan sediaan farmasi, alat kesehatan dan BMPH harus berpedoman pada beberapa regulasi atau peraturan berikut ini:

1. Petunjuk Teknis Pelaksanaan Standar Pelayanan Kefarmasian di Apotek (SK nomor 1027/MENKES/SK/IX/2004) [3]

2. Kepmenkes RI Nomor : 347/MenKes/SK/VII/1990 tentang Obat Wajib Apotik [5]

3. PMK Nomor 924/MENKES/PER/X/1993 tentang Daftar Obat Wajib Apotek No.2 [6]

4. Kepmenkes RI Nomor : 1176/MenKes/SK/X/1999 tentang Daftar Obat Wajib Apotek No.3 [7]

5. Peraturan BPOM Nomor 4 tahun 2018 tentang Pengawasan Pengelolaan Obat, Bahan Obat, Narkotika, Psikotropika, dan Prekursor Farmasi di Fasilitas Pelayanan Kefarmasian [8]

6. Peraturan BPOM Nomor 7 tahun 2016 Pedman Pengelolaan Obat-Obat Tertentu yang Sering Disalahgunakan [9].

Berdasarkan hal tersebut, pengadaan sediaan farmasi di apotek secara umum dilakukan dengan SOP seperti yang tertera pada Gambar 1 . Dalam proses pengadaan ini, terdapat beberapa hal yag harus diperhatikan seperti pemasok sediaan farmasi adalah Pedagang Besar Farmasi (PBF) yang memiliki izin; Alat Kesehatan dan BMHP diperoleh dari Penyalur Alat Kesehatan (PAK) yang memiliki izin; terjaminnya keaslian, legalitas dan kualitas produk yang dibeli; sediaan farmasi, alat kesehatan dan BMHP yang dipesan datang tepat waktu; dokumen terkait sediaan farmasi, alat kesehatan dan BMHP mudah ditelusuri; dan sediaan farmasi, alat kesehatan dan BMHP lengkap sesuai dengan perencanaan [3].

Penelitian ini bertujuan untuk untuk mengetahui gambaran sistem manajemen perencanaan pengadaan sediaan farmasi, alat kesehatan, dan BMHP yang diterapkan di Apotek untuk pemenuhan kebutuhan konsumen serta kesesuaiannya dengan Petunjuk Teknis Standar Pelayanan Kefarmasian di Apotek. Dengan adanya publikasi terkait sistem manajemen perencanaan yang optimal, maka diharapkan dapat meningkatkan kualitas pelayanan kefarmasian khususnya dalam ruang lingkup Apotek. Penelitian ini menggunakan metode deskriptif observational dengan perolehan data kualitatif untuk memberikan gambaran mengenai sistem perencanaan pengadaan sediaan farmasi, alat kesehatan, dan bahan medis pakai di Apotek, serta didukung dengan data kuantitatif yang diambil secara retrospektif dari dokumen yang 
tersedia di Apotek. Objek dalam penelitian ini dikhususkan pada salah satu Apotek di wilayah Kabupaten Badung,

Provinsi

Bali.

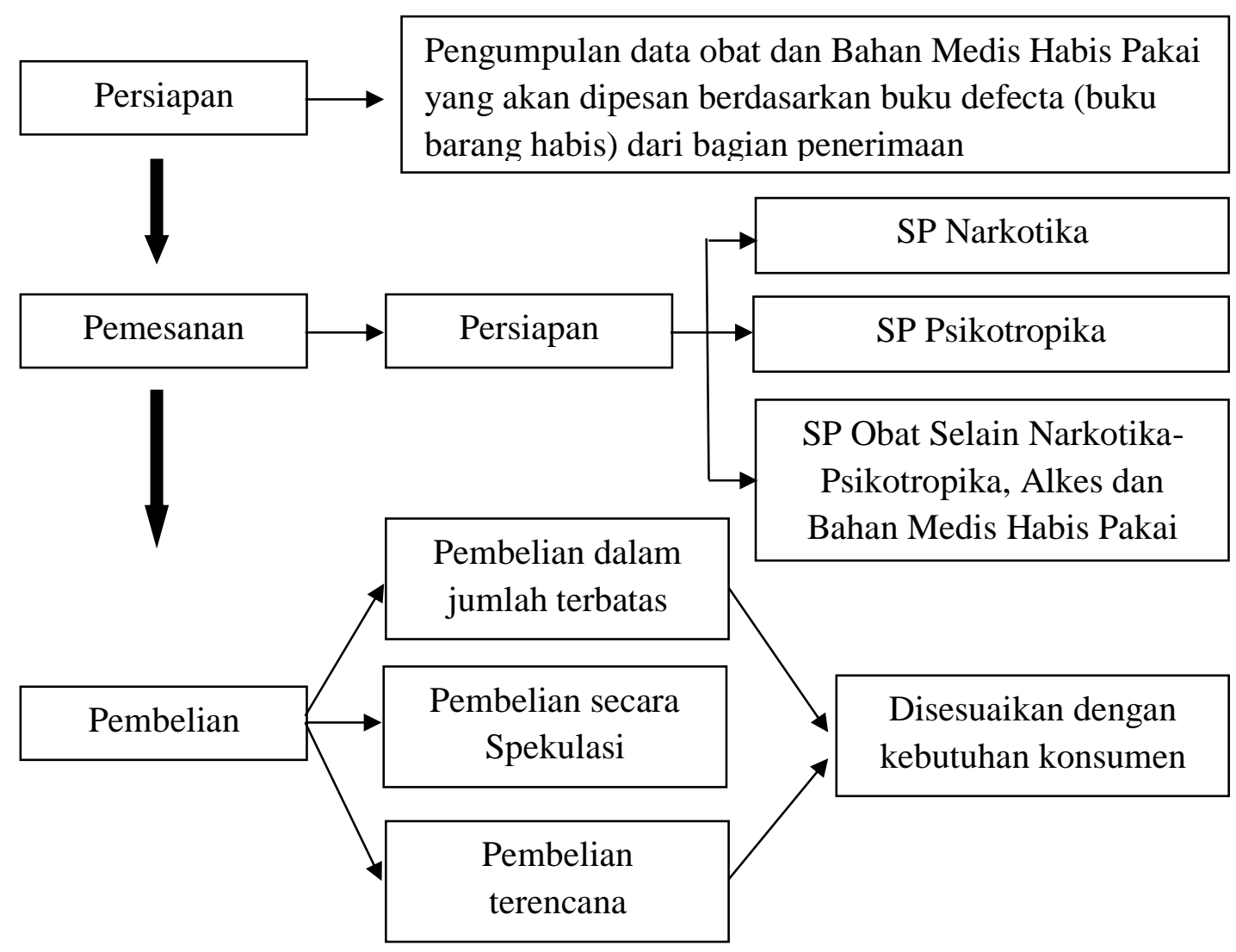

Outcome: Tersedianya sediaan farmasi, alkes, dan bahan medis habis pakai dengan jumlah dan jenis yang cukup sesuai dengan kebutuhan pelayanan di Apotek

Gambar 1. Flowchart SOP Pengadaan Sediaan Farmasi, Alat Kesehatan, dan Bahan Medis Habis Pakai di Apotek

\section{METODE PENELITIAN}

\section{Bahan dan Peralatan}

Sampel pada penelitian ini adalah salah satu Apotek yang berlokasi di wilayah Kabupaten Badung. Instrumen yang digunakan pada penelitian ini adalah lembar isian observasi dengan melakukan pengamatan langsung dan wawancara terhadap sampel dan mencatat kondisi di lapangan sesuai dengan lembar isian observasi yang telah disusun.

\section{Metode}

Metode yang digunakan dalam penelitian ini adalah deskriptif observational. Data kualitatif diperoleh dengan cara melakukan 
wawancara terhadap apoteker pengelola apotek yang bertugas di apotek tersebut. Wawacara ini berkaitan dengan metode perencanaan sediaan farmasi, alat kesehatan, dan BMHP serta kesesuaian prosedurnya dengan Permenkes RI No 73 tahun 2016. Selain itu data kuantitatif diambil secara retrospektif untuk mengetahui omset penjualan dari bulan, data produk expired date (ED), persentase barang fast moving dan slow moving dan dokumen lain periode Januari-Mei 2020 yang berkaitan dengan perencanaan di Apotek X. Pengolahan data dilakukan dengan menyajikan data dalam bentuk tabel.

\section{HASIL dan PEMBAHASAN}

Apotek merupakan salah satu fasilitas pelayanan kesehatan bagi masyarakat. Pasien dapat membeli obat ataupun menukarkan resep di Apotek. Apoteker pengelola apotek bertanggungjawab atas perencanaan pengadaan sediaan farmasi di Apotek. Perencanaan bertujuan untuk menyusun kebutuhan obat yang tepat dan sesuai dengan kebutuhan untuk mencegah terjadinya kekurangan atau kelebihan persediaan farmasi serta meningkatkan penggunaan persediaan farmasi secara efektif dan efisien [2]. Di samping itu, hal terpenting yang juga harus diperhatikan dalam hal ketersediaan obat ialah harus tepat jenis dan jumlahnya harus sesuai dengan pola penyakit dan kebutuhan pada pelayanan kesehatan [11].

Berdasarkan hasil wawancara dengan narasumber Perencanaan di Apotek X melibatkan apoteker pengelola apotek, tenaga teknis kefarmasian, dan karyawan. Dari ketiga metode perhitungan yang ada, Apotek $\mathrm{X}$ memilih menggunakan metode Proxy Consumption yang merupakan perhitungan kebutuhan berdasarkan epidemiologi penyakit dan konsumsi masyarakat. Narasumber berpendapat bahwa metode ini adalah metode yang paling efektif dan efisien untuk perhitungan kebutuhan sedian farmasi, alat kesehatan dan BMHP. Terdapat tiga hal yang harus diperhatikan dalam perencanaan pengadaan sediaan farmasi, alat kesehatan dan BMHP, yaitu jumlah, jenis dan waktu. Narasumber berpendapat bahwa perencanaan pengadaan adalah faktor kunci sebuah apotek karena dapat meningkatkan cash flow dan meningkatkan pelayanan kepada konsumen.

Standar Operasional Prosedur (SOP) perencanaan di Apotek $\mathrm{X}$ digambarkan dalam Gambar 2, yang mana diawali dengan melakukan seleksi atau penilaian terhadap jenis sediaan farmasi dan alat kesehatan yang diperlukan, melakukan perencanaan dengan mempertimbangkan tingkat kebutuhan, jumlah anggaran, pola penyakit, dan tingkat penggunaan obat periode sebelumnya, Apoteker melakukan review terhadap kemampuan daya beli masyarakat, melakukan kompilasi pemakaian obat setiap bulan dengan cara menghitung stok optimum sebagai dasar untuk menentukan jumlah sediaan farmasi dan alat kesehatan yang dibutuhkan untuk memenuhi kebutuhan 
pelayanan, dan menyusun perkiraan perencanaan kebutuhan sediaan farmasi dan alat kesehatan serta perkiraan pembelian. Proses tersebut telah sesuai dengan standar pelayanan kefarmasian serta diadaptasikan dengan kondisi atau kebutuhan apotek [3]. Dokumen yang diperlukan pada tahap perencanaan ini adalah kartu stok dan lembar hasil stok opname. Dalam melakukan perencanaan, apoteker di Apotek $X$ juga memerhatikan DOEN (Daftar Obat Esensia Nasional), dan anggaran yang tersedia. Menurut Narasumber, sistematika perencanaan yang dibuat menyesuaikan dengan jumlah anggaran yang disediakan agar tidak terjadi defisit.

Selain melakukan perhitungan kebutuhan sediaan farmasi, alat kesehatan dan BMHP, apoteker di Apotek $\mathrm{X}$ juga melakukan analisis rencana kebutuhan sediaan farmasi sebagai bagaian dari perencanaan pengadaan sediaan farmasi yang bertujuan untuk menjamin ketersediaan obat dan efisiensi anggaran. Metode analisis yang dipilih adalah analisis ABC (Pareto).

Metode ini dilakukan dengan menyesuaikan rencana pengadaan obat dengan jumlah dana yang tersedia, sehingga skala prioritas obat dan jumlah obat yang akan dibeli dapat dioptimalkan untuk menjamin ketersediaan obat yang bermutu tinggi, tepat jenis, tepat jumlah, dan tepat waktu untuk dapat digunakan secara rasional [10]. Penggunaan metode Pareto (ABC) untuk penyediaan obat dimaksudkan untuk memprioritaskan perencanaan pembelian obat yang sering digunakan dan biasanya jenisnya sedikit akan tetapi mempunyai biaya investasi yang besar. Selain itu, tanpa memperhatikan harga perlu juga dipertimbangkan pengendalian obatobat yang paling banyak dikonsumsi masyarakat agar pelayanan kesehatan tetap dapat berjalan optimal.

Dengan menggunakan metode perencanaan tersebut, apotek $\mathrm{X}$ menghasilkan omset rata-rata adalah Rp. 40.000.000/bulan dihitung dari omset penjualan periode Januari-Mei. Selain itu bila dilihat dari persentase barang fast moving dan slow moving yaitu $60 \%$ dan $40 \%$. Terkait dengan expired date (kadaluarsa), narasumber menjelaskan bahwa tidak terdapat produk yang kadaluarsa karena staff apotek rutin melakukan pengecekan barang dan apotek juga telah bekerjasama dengan distributor atau PBF untuk pengembalian barang tiga bulan sebelum expired date produk tersebut. Hal tersebut merupakan suatu strategi yang dilakukan oleh apoteker untuk menjamin pengelolaan sediaan farmasi dapat berlangsung dengan baik. Dengan menggunakan metode Proxy Consumption untuk perhitungan kebutuhan sediaan farmasi dan metode analisis ABC maka akan lebih mudah untuk memperhitungkan produk yang dibutuhkan oleh masyarakat sehingga dapat meminimalisir adanya barang atau produk yang expired date. 


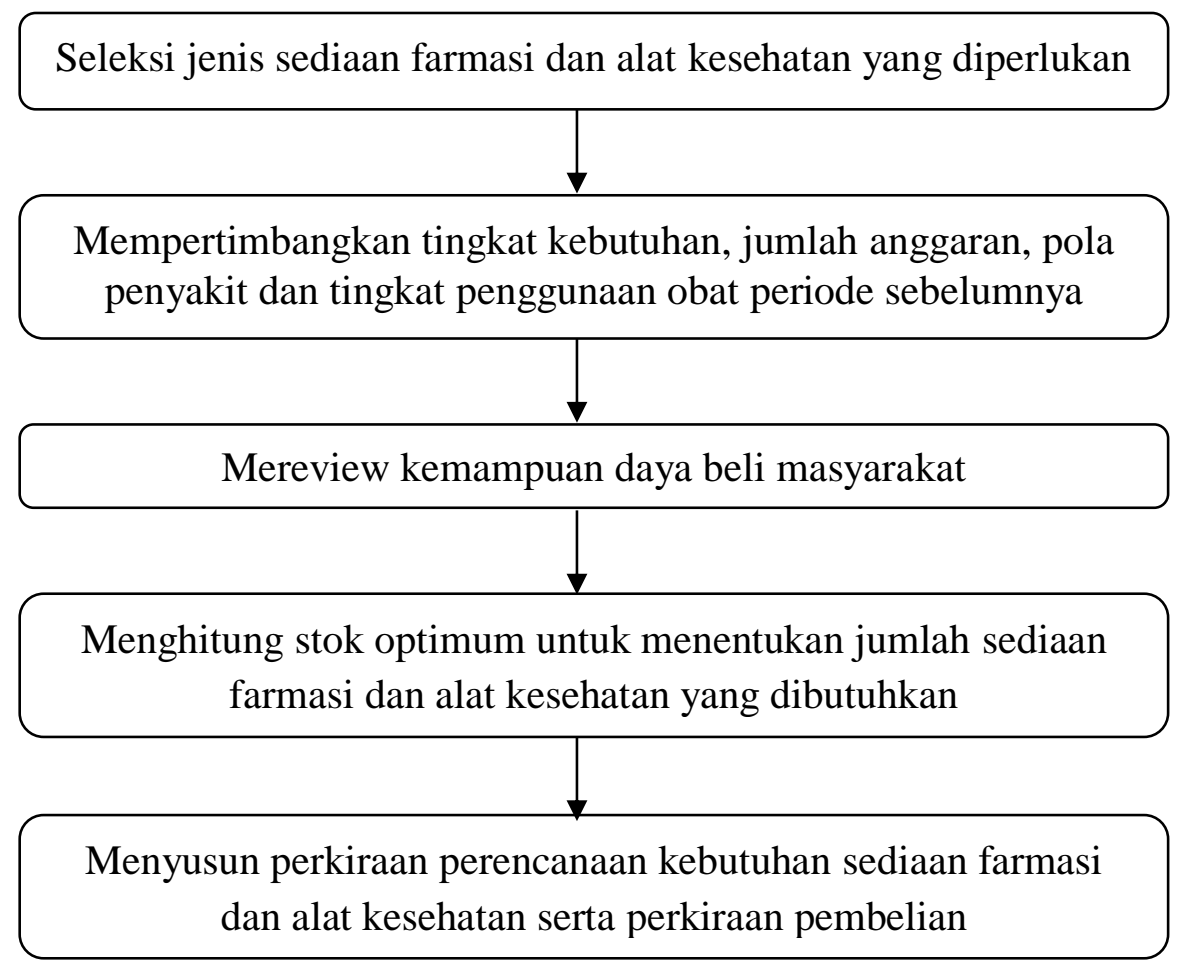

Gambar 2. Bagan Alur Standar Operasional Prosedur Perencanaan di Apotek X

Tabel 1. Hasil Observasi di Apotek X

\begin{tabular}{cc}
\hline Indikator & Hasil \\
\hline Metode Perhitungan Kebutuhan & Proxy Consumption \\
Metode Analisis Perencanaan & Analisis ABC (Pareto) \\
Rata-rata omset & Rp. 40.000.000/bulan \\
Persentase barang fast moving & $60 \%$ \\
Persentase barang slow moving & $40 \%$ \\
Kerugian Expired & Rp. 0 \\
\hline
\end{tabular}

Kompetensi yang harus dimiliki seorang apoteker untuk dapat melakukan perencanaan pengadaan sediaan farmasi di Apotek adalah mampu menghitung rencana pengadaan sediaan farmasi, alat kesehatan, dan bahan medis habis pakai dengan tepat; memilih sediaan farmasi, alat kesehatan dan bahan medis habis pakai sesuai dengan kebutuhan masyarakat dengan memperhatikan pola prevalensi 
penyakit, ketersediaan sarana pelayanan kesehatan, faktor sosial ekonomi dan budaya masyarakat, sumber daya manusia, genetika, demografi dan lingkungan. Untuk itu seorang apoteker harus memahami ilmu farmasi yang terkait dengan hal tersebut.

Berdasarkan hasil wawancara, narasumber mengatakan bahwa agar dapat menjalankan tupoksinya dalam melakukan perencanaan dengan baik, maka seorang apoteker harus memahami ilmu manajemen farmasi, farmakoterapi, dan epidemiologi dengan baik. Ketiga ilmu farmasi tersebut adalah suatu landasan yang dapat digunakan dalam melakukan perencanaan pengadaan sediaan farmasi agar sesuai dengan kebutuhan masyarakat pada pelayanan kesehatan.

Ilmu manajemen farmasi merupakan suatu ilmu yang digunakan dalam usaha atau kegiatan agar kegiatan mampu terlaksanan dengan efektif dan efisien dalam mencapai tujuan yang telah ditetapkan[10]. Ilmu epidemiologi merupakan ilmu yang mempelajari tentang ditribusi atau pola penyakit pada populasi tertentu. Dengan memahami ilmu epidemiologi, seorang apoteker diaharapkan mampu menentukan pola penyakit di masyarakat sehingga dapat mempermudah perencanaan yang dilakukan [12], karena dalam perhitungan kebutuhan sediaan farmasi dengan menggunakan metode Proxy Consumption harus ditentukan pola penyakit masyarakat [13]. Ilmu Farmakoterapi berperan dalam terapi yang tepat bagi pasien.

\section{KESIMPULAN}

Perencanaan di Apotek X yang merupakan salah stau apotek yang berada di wilayah Kabupaten Badung sudah dilaksanakan sesuai dengan Standar Pelayanan Kefarmasian di Apotek yang tertera pada Peraturan Menteri Kesehatan Republik Indonesia Nomor 73 Tahun 2016. Metode perhitungan kebutuhan sediaan farmasi yang digunakan adalah metode Proxy Consumption yang mengombinasikan Metode Konsumsi dan metode Epidemiologi (Morbiditas). Metode ini dianggap strategis untuk perhitungan kebutuhan sediaan farmasi, sehingga dapat memenuhi kebutuhan masyarakat dalam pelayanan kesehatan. Selain perhitungan kebutuhan, untuk menilai efisiensi perencanaan, maka dilakukan analisis terhadap perencanaan dengan menggunakan metode ABC atau Pareto. Metode ini dapat meminimalisir adanya barang expired date serta dapat menghasilkan persentase barang fast moving yang lebih tinggi dibandingkan persentase barang slow moving.

\section{UCAPAN TERIMA KASIH}

Terimakasih saya ucapkan kepada seluruh pihak yang terlibat dalam penyusunan artikel ini, khususnya Apoteker Pengelola Apotek X yang telah berkenan sebagai narasumber hinga terselesaikanya artikel ini, dan seluruh karyawan Apotek X.

\section{DAFTAR PUSTAKA}

[1] Anderson, P. D. 2012. The Broad Field of Forensic 
Pharmacy. Journal of Pharmacy Practice. 25 (1): 7-12.

[2] Kemenkes RI, 2016. Peraturan Menteri Kesehatan Republik Indonesia Nomor 73 Tahun 2016 tentang Standar Pelayanan Kefarmasian di Apotek. Jakarta: Kementerian Kesehatan Repubik Indonesia.

[3] Kemenkes RI. 2019 Petunjuk Teknis Standar Pelayanan Kefarmasian di Apotik. Jakarta: Kementerian Kesehatan Republik Indonesia

[4] Devnani, M., Gupta, A.K., Nigah, R., 2010. ABC And VED Analysis Of The Pharmacy Store Of A Tertiary Care Teaching, Research And Referral Healthcareinstitute Of India. Journal of Young Pharmacists 2(2):201-205.

[5] Kemenkes RI. 1990. Kepmenkes RI

Nomor:347/MenKes/SK/VII/199 0 tentang Obat Wajib Apotik. Jakarta: Kementerian Kesehatan Republik Indonesia.

[6] Kemenkes RI. 1993. PMK Nomor:

924/MENKES/PER/X/1993

tentang Daftar Obat Wajib Apotek No.2. Jakarta: Kementerian Kesehatan Republik Indonesia.

[7] Kemenkes RI. 1999. Kepmenkes RI Nomor:

1176/MenKes/SK/X/1999

tentang Daftar Obat Wajib Apotek No.3. Jakarta: Kementerian Kesehatan Republik Indonesia.
[8] BPOM RI. 2018. Peraturan BPOM Nomor 4 tahun 2018 tentang Pengawasan Pengelolaan Obat, Bahan Obat, Narkotika, Psikotropika, dan Prekursor Farmasi di Fasilitas Pelayanan Kefarmasian. Jakarta: Badan Pengawas Obat dan Makanan Republik Indonesia.

[9] BPOM RI. 2016. Peraturan BPOM Nomor 7 tahun 2016 Pedman Pengelolaan Obat-Obat Tertentu yang Sering Disalahgunakan. Jakarta: Badan Pengawas Obat dan Makanan Republik Indonesia.

[10] Quick, JD., Rankin, Dias, Vimal. 2012. Inventory Managemen Drug Supply. Third Edition, Managing access to medicines and health technologies. Arlington: Management Sciences for Health. Managing.

[11] Departemen Kesehatan RI., 2004. Sistem Kesehatan Nasional. Departemen Kesehatan RI, Jakarta.

[12] Amiruddin, R. S. 2013. Kesehatan Masyarakat. Bogor: IPB Press

[13] Setiani, N. 2012. Laporan Praktek Kerja Profesi Apoteker di Direktorat Bina Produksi dan Distribusi Kefarmasian, Direktorat Jenderal Bina Kefarmasian dan Alat Kesehatan, Kementerian Kesehatan Republik Indonesia Periode 16 Januari-27 Januari 2012. Depok: Fakultas Farmasi, Program Profesi Apoteker, Universitas Indonesia. 